\section{Автоматизация разбраковки фанеры методом свободных колебаний}

\author{
Е. В. Саликова ${ }^{1}$ \\ Б. А. Староверов \\ В. А. Изотов \\ Костромской государственный технологический \\ университет
}

\begin{abstract}
АННОТАЦИЯ
В статье рассматриваются вопросы автоматизации разбраковки фанеры с применением метода свободных колебаний. Проведенные эксперименты показали достаточную информативность предложенного метода. На основе данной технологии можно практически реализовать автоматизированную установку для разбраковки фанеры на ранних стадиях производства.
\end{abstract}

Ключевые слова: фанера, разбраковка, неразрушаюшиий контроль, пьезодатчик.

\section{SUMMARY}

The questions of plywood culling with application of free oscillations method are examined in the article. The carried out experiments have shown that the offered method is sufficiently informative. On the basis of the given technique it is possible practically to realize the automized installation for culling of plywood at early stages of manufacture.

Keywords: plywood, culling, not destroying monitoring, piezodetector.

При производстве фанеры возможно появление в ней внутренних дефектов (пузырей и вздутий), наличие которых в готовой продукции является недопустимым. Причины образования внутренних дефектов обусловлены, в основном, нарушениями технологического процесса производства фанеры и нестабильностью качества исходного сырья.

На отечественных предприятиях, на фоне применения современных средств автоматизации на большинстве участков производства фанеры, контроль качества готовой продукции осуществляется вручную на заключительной стадии производства. Ручной метод выявления внутренних дефектов заключается в простукивании листов и определении наличия брака «на слух». Такой метод достаточно эффективен, но имеет ряд принципиальных недостатков, а именно: он не позволяет локализовать вид и размер дефекта; оценка качества фанеры субъективна, зависит от квалифика-

\footnotetext{
${ }^{1}$ Авторы - соответственно аспирант и профессор кафедры автоматики и микропрочессорной техники и доиент кафедры электротехники и электромеханики

(C) Е. В. Саликова, Б. А. Староверов, В. А. Изотов, 2003
}

ции работника; работа контролера физически тяжелая и монотонная.

Наиболее распространенным методом автоматизированного неразрушающего контроля материалов и изделий является ультразвуковой. Этот метод успешно используется для контроля фанеры на зарубежных предприятиях и ряде отечественных. В процессе контроля фанерный лист «просвечивается» с помощью источника ультразвука. Ультразвуковые приемники улавливают отраженный или прошедший сквозь фанеру ультразвук, по интенсивности которого можно судить о плотности фанеры и таким образом определять вид и размеры имеющихся в фанере дефектов [1]. Метод достаточно точен, технологичен, позволяет автоматизировать процесс разбраковки фанеры. Результаты измерений можно использовать как для селективной разбраковки фанеры, так и для автоматизированной корректировки технологических процессов изготовления фанеры. Однако ультразвуковой метод также имеет существенные недостатки, а именно: для контроля данным методом требуются достаточно стабильные внешние условия (температуpa, качество поверхности фанеры, отсутствие конвекционных воздушных потоков и т.д.), что усложняет конструкцию измерительной установки; реализация метода требует сравнительно больших затрат.

В связи с этим была поставлена задача создать систему автоматизированной разбраковки фанеры, основанную на методе возбуждения свободных колебаний [2]. Сущность метода свободных колебаний заключается в следующем. Если твердое тело возбудить резким ударом, то в нем возникнут свободные затухающие колебания. При наличии дефекта параметры колебательной системы меняются, что ведет к изменению амплитуды, частоты собственных колебаний и логарифмического декремента их затухания.

Техническая реализация метода свободных колебаний проще. Разбраковочная система может быть более мобильной, что делает возможным ее установку и после заключительного этапа производства и непосредственно после прессования. В последнем случае брак определяется на ранней стадии производства, что позволит исключить бракованные листы из дальнейшей обработки и получить, таким образом, дополнительный экономический эффект.

Схема экспериментальной установки для автоматизированной разбраковки фанеры методом свободных колебаний представлена на рис. 1, где:

БП - блок питания; СУ - система управления; УВМ управляющая вычислительная машина; 1 - электромагнитная защелка; 2 - держатель; 3 - пьезодатчик; 4 - опора; 5 - ударный механизм (шарик); 6 - исследуемый лист фанеры; 7 - направляющие (двухкоординатный механизм).

Управление работой установки осуществляется программой с помощью УВМ. Программа реализует следующий алгоритм работы. После команды «Пуск» электромагнитная защелка освобождает ударный 
механизм (шарик), который падает с фиксированной высоты и вызывает колебания листа фанеры.

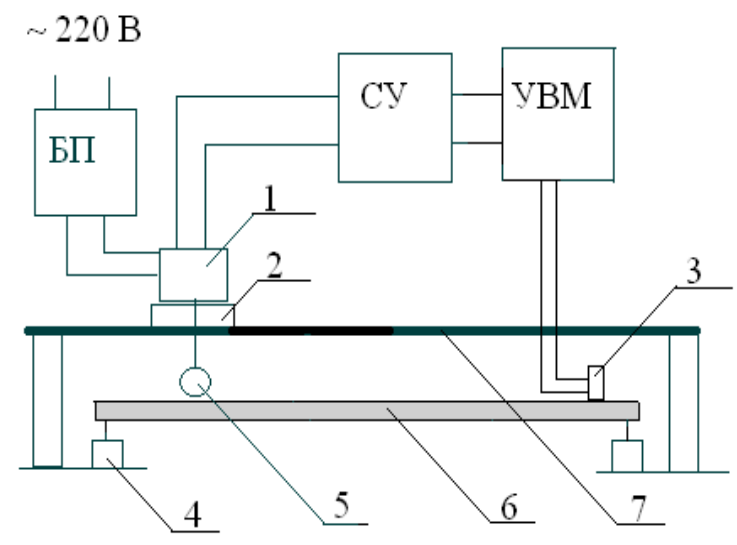

Рис. 1. Схема экспериментальной установки для определения качества фанеры методом свободных колебаний

Создающиеся при этом звуковые колебания фанеры фиксируются пьезодатчиком. Усиленный звуковой сигнал подается на УВМ через аналого-цифровой преобразователь (АЦП) и записывается в виде графика затухающих колебаний в память машины.

Для исследования были использованы стандартные листы фанеры $1525 \times 1525$ мм толщиной 6,12 и 15 мм, прошедшие контроль ОТК ручным способом. Для локализации дефектов испытуемые листы были разбиты на шестнадцать квадратов. Таким образом, каждый лист подвергался шестнадцати ударным воздействиям

Исследования проводились с применением нескольких видов датчиков. Первоначально в качестве первичного преобразователя применяли микрофон. Обработка результатов эксперимента показала, что частотные области свободных колебаний качественных и дефектных листов достаточно хорошо различаются [3]. Но данный способ имеет ряд недостатков, а именно: значительное влияние внешних помех; микрофон и ударный механизм должны располагаться в непосредственной близости друг от друга.

Для дальнейших исследований использовали в качестве первичного преобразователя пьезодатчики. Проведенные исследования показали, что местоположение пьезодатчика на листе фанеры не влияет на результаты измерения. Таким образом, датчик фиксированно устанавливался на краю листа фанеры.

Типичные графики свободных колебаний листа фанеры представлены на рис. 2 и 3.

Для анализа графиков применялась технология искусственных нейронных сетей. В данном случае искусственная нейронная сеть выступает в качестве распознающего устройства, которое в зависимости от параметров относит колебание к одному из двух классов: принадлежащее листу фанеры без брака или имеющему брак. В работе использовалась нейронная сеть, относящаяся к типу многослойных персептронов с обратным распространением ошибки. Обученная нейронная сеть правильно идентифицировала все представленные случаи графиков как для фанеры без брака, так и для фанеры, имеющей брак.

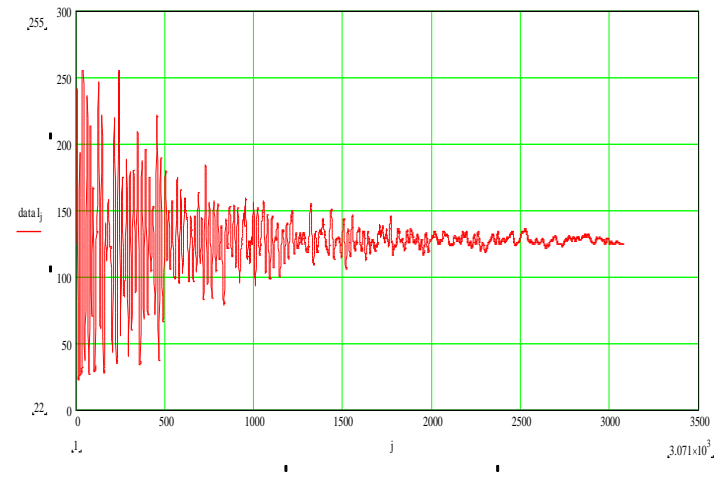

Рис. 2. График свободных колебаний листа фанеры без брака

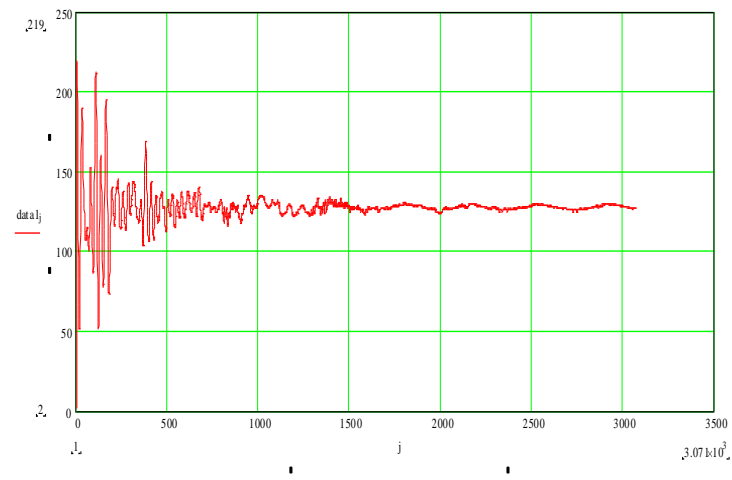

Рис. 3. График свободных колебаний листа фанеры, имеющей брак

Это свидетельствует, что на основе данной технологии можно практически реализовать автоматизированную установку для разбраковки фанеры на ранних стадиях производства.

\section{СПИСОК ЛИТЕРАТУРЫ}

1. Голубов И. А. Методы неразрушающего контроля древесных плит. М.: Лесн. промышленность, 1982.

2. Глаговский Б. А., Московенко И. Б. Низкочастотные акустические методы контроля в машиностроении. Л.: Машиностроение, 1977.

3. Саликова Е. В., Староверов Б. А., Чулков В. П. Автоматизированная разбраковка фанеры методом звуковой диагностики // Вестник Костромского государственного технологического университета. 2003. № 7. 